\title{
Training professionals to improve media accessibility
}

\author{
Estella Oncins \\ Universitat Autònoma de Barcelona, Spain \\ Anna Matamala \\ Universitat Autònoma de Barcelona, Spain
}

\begin{abstract}
COVID-19 has affected all areas of our lives, and cinema, as part of culture, is no exception. New and existing technologies applied to audiovisual products are changing the way in which we provide and access culture.

Nobody challenges the importance of having accessible audiovisual content. This is the aim of the recently approved European Directives following the ratification of the UN Convention on the Rights of Persons with Disabilities (UNCRPD). The new European legislative framework must guarantee the full and democratic participation of all citizens in the new information society. It is crucial to ensure access to technology and content for all citizens.

The objective of this article is to present the new professional profiles in the accessibility field that have been developed in the last decades through Erasmus+ projects initiatives. First, the current European legislative framework on accessibility will be outlined. Then, the main accessibility services available in the media field will be explained. Next, the professional profiles in accessibility will be presented together with the emerging new profiles and Erasmus+ projects. Finally, the conclusions will outline the existing needs and improvements in the education and training of new professionals in media accessibility.
\end{abstract}

Keywords: Media Accessibility, Audio Description, subtitles for the Deaf and Hard of Hearing, Easy Language, Web accessibility.

\section{Introduction}

The recent adoption of laws and policies at international, European, and national levels has placed accessibility at the forefront, requiring the countries of the European Union to ensure that any user can access and interact with any software, web content, documents, and hardware regardless of their capabilities. Accessibility is a right to equal opportunities for all citizens. Article 9 of the United Nations Convention on the Rights of Persons with Disabilities ${ }^{1}$ (CRPD 2006) deals with accessibility and states that

To enable persons with disabilities to live independently and participate fully in all aspects of life, States Parties shall take appropriate measures to ensure to persons with disabilities access, on an equal basis with others, to the physical environment, to transportation, to information and communications, including information and communications technologies and systems, and to other facilities and services open or provided to the public, both in urban and in rural areas.
In 2010, this document was ratified by the European Union and the EU Member States and, consequently, three main pieces of legislation have been put in place: the Web Accessibility Directive (WAD 2016), the updated Audiovisual Media Services Directive (AVMSD 2018), and the European Accessibility Act (EAA 2019). This European legislative framework is currently being transposed to the different EU countries, and the national standardisation agencies have to adapt their laws in order to ensure not only access to media but also to accessible services for all citizens. The main accessibility services are subtitles for the Deaf and Hard of Hearing (SDH), sign language (SL), audio subtitles, audio description $(A D)$, and Easy Language (EL). Since there is no EU standard for these accessibility services, the AVMSD only measures the quantity of programmes being broadcasted with each service (Matamala and Orero 2018). In this regard, the European Disability Forum (EDF), in its document "Audiovisual Media Service Directive - Toolkit for transposition"2 (2019), offers an example for a gradual and progressive transposition of the AVMSD in a Member State (see table 1).

\begin{tabular}{|l|c|l|l|l|l|}
\hline $\begin{array}{l}\text { Accessibility } \\
\text { service/ Year }\end{array}$ & $\mathbf{2 0 2 0}$ & $\mathbf{2 0 2 1}$ & $\mathbf{2 0 2 2}$ & $\mathbf{2 0 2 3}$ & $\mathbf{2 0 2 4}$ \\
\hline SDH & $20 \%$ & $40 \%$ & $60 \%$ & $80 \%$ & $100 \%$ \\
\hline SL & $7 \%$ & $10 \%$ & $12 \%$ & $15 \%$ & $18 \%$ \\
\hline AD & $7 \%$ & $8 \%$ & $10 \%$ & $12 \%$ & $15 \%$ \\
\hline Audio subtitles & $20 \%$ & $40 \%$ & $60 \%$ & $80 \%$ & $100 \%$ \\
\hline
\end{tabular}

Table 1. Example of gradual and progressive transposition of the AVMSD (source: EDF 2019)

As can be observed, the percentages required for $A D$ and $S L$ are relatively low compared to SDH or audio subtitles. It can be considered a starting point and a reference point that will increase in the coming years.

\section{Accessibility services}

In order to achieve an appropriate level of audiovisual and digital accessibility in the different media content services, products and tools, there are guidelines and standards that Member States, organisations and professionals offering accessibility services must consider. The following section presents an overview of the main accessibility services that are covered at a European level. 


\subsection{Subtitling for the Deaf and Hard of Hearing (SDH)}

Subtitling is the accessibility service with the widest implementation and legislation coverage. According to the European Broadcasting Union report (EBU 2019), all public broadcasters offer subtitling, while only two thirds offer the three main accessibility services: subtitling, audio description, and sign language in some of their content.

Many countries in the world have laws, standards, or regulations for subtitling in place, such as the ISO standard (ISO/IEC 20071-23:2018). At a national level, for instance, subtitling in Spain is regulated by the AENOR standard UNE 153010. Standards include three main fundamental aspects: target users who will benefit from the service (Deaf and/or Hard of Hearing people), optionality (open or closed), and time coding (live or pre-recorded). The latter is one of the most problematic aspects in terms of production. While pre-recorded subtitling has long been implemented in different media contexts, live subtitling is more recent and involves greater challenges for professionals, especially in the case of spontaneous and unscripted speeches (Lambourne 2006). According to the EBU report (2019), respeaking is the technique most used by televisions for the creation of live subtitles. Eugeni (2016, 159) defines respeaking as, "a reformulation, a translation or a transcription of a text, produced by the respeaker, processed by a speech recognition software and being broadcast simultaneously with the production of the original text". It should be noted that live subtitling requires different skills than pre-recorded subtitling, one of them being the able to listen and speak at the same time while reproducing the source text as accurately as possible regardless of the technique used. Current training of professionals in this area has mainly focused on live subtitling for the TV broadcasting context, with less attention to other contexts such as parliament, conferences, or educational contexts. The LTA project ${ }^{3}$ (2018-2022) focuses on the training of live subtitling professionals for different working contexts, thus filling a gap in this field.

\subsection{Audio description (AD)}

In 2008, Spain was the only country with a written standard for audio description, the AENOR standard "Standard UNE 153020: 2005: Requirements for audio description" (Puigdomènech et al. 2008). Nowadays, audio description is an accessibility service that is practiced and studied around the world and there is also an ISO standard that deals with it (ISO/ IEC TS 20071-21:2015). In the last decades, research and implementation of audio description services has increased considerably. However, according to Reviers (2016), the provision of this service in the different EU countries continues to be irregular and depends on the norms and legislation in force in each country. Different studies have emphasised the importance of creating a European audio description standard (Orero 2005a,
Vercauteren 2007). In this regard, the main objective of the ADLAB project ${ }^{4}$ (2011-2014) was to identify inconsistencies in the creation and implementation of the audio description service at the European level. Additionally, the objective of the ADLAB PRO project ${ }^{5}$ (2016-2019) was the definition of a unified curriculum to guarantee the training of professionals in audio description throughout Europe for different working contexts. The ADLAB PRO materials are open access and available on the project website.

\subsection{Audio subtitling}

Audio subtitles or spoken subtitles are useful mainly to provide access to foreign language content with subtitles for people with low vision, the elderly, people with language disorders such as aphasia, dyslexia, or with cognitive disabilities (Theunisz 2002). They can be offered as an independent service or integrated with audio description. Audio subtitling is not a very widespread accessibility service. Most European countries do not offer this service and it is mainly available in European Nordic countries (Braun and Orero 2010). ISO has developed a specific technical specification on this service (ISO/IEC TS 2000071:25:2017).

\subsection{Sign Language (SL)}

Sign language is one of the areas of accessibility with the lowest coverage. Although the number of weekly hours defined by the AVMSD that must be covered with this service has increased in recent years, the number of hours remains below average in most countries (García-Prieto 2018, Bosch-Baliarda et al. 2020) and, more importantly, the quality of accessible content in terms of on-screen representation is uneven (Bosch-Baliarda et al. 2020). Even if SL dates back to the 1970s, this accessibility service remains an underdeveloped and under-researched accessibility service. In fact, there is no specific published international standard for this service. In some countries, sign language is regulated by norms and standards, as in the case of Spain with the UNE standard (139804:2007). Additionally, the training of professionals in this field is covered mainly at a vocational level rather than at an academic level.

\subsection{Easy Language (EL)}

Easy Language (or Easy-to-Read in its traditional terminology) is beginning to be incorporated in audiovisual access services in order to improve comprehension (Bernabé and Orero 2019). According to Matamala (2019), EL is a way of writing texts that avoids the use of complicated language to ensure that the reader easily understands the written text. The recent incorporation of this accessibility modality results in a considerable lack of professionals trained in $E L$, as in most countries the accessibility service has to be validated by professionals. At an international level, this service is included in the ISO standard 
(ISO/IEC CD 23859-1). At a national level, in some countries the creation of EL content is regulated by norms and standards, as in the case of Spain with the UNE standard (153101: 2018), which provides guidelines and recommendations for the elaboration of documents in Easy-to-Read. Still, there is much to be done in this field. The development of guidelines, as well as support for training initiatives such as the Erasmus+ EASIT project ${ }^{6}$ (2018-2021), is crucial.

\subsection{Web accessibility}

Web accessibility could be considered an umbrella that encompasses the different accessibility services detailed in the previous section $(\mathrm{SDH}, \mathrm{AD}$, audio subtitles, SL and EL). It also includes additional requirements that must be met in order to ensure that accessible contents and products can be reached by users. At a European level, the Web Accessibility Directive (2016) sets the standard requirements for web accessibility products and services across the EU. Member States must ensure that websites and mobile applications of public sector bodies are more accessible, particularly for persons with disabilities. It aims at: a) harmonising the Internal Market for web accessibility products and services and b) increasing digital and social inclusion by making the websites and mobile applications of public sector bodies more accessible for citizens, especially citizens with disabilities, based on common accessibility requirements. The directive does not include any of the rules that websites and mobile applications need to follow to stay in compliance. To this aim, there is the harmonised European standard EN 301549 "Accessibility requirements for ICT products and services"7, which provides guidance and includes the Web Content Accessibility Guidelines (WCAG) $2.1^{8}$. This standard establishes a model of accessibility declaration in accordance with the directive, defines the information that must be provided, and the requirements that web pages and mobile applications must meet in order to be accessible. In terms of implementation, each European Member State has to transpose the directive into national laws. For instance, web accessibility in Spain is regulated by UNE 139803:2012, which establishes the accessibility requirements for web content. On the other hand, the standard UNE-EN 301549:2019 establishes the functional requirements that guarantee that ICT products and services are accessible to all people.

It is recommended to follow the Web Content Accessibility Guidelines (WCAG) 2.1, which are also an ISO standard (ISO/IEC 40500:2012). These guidelines aim to promote web accessibility for all users regardless of the ICT service, product, and tool. The objective is to provide a single shared standard for web accessibility that ensures access to digital and media content for all citizens. On many occasions, a web developer creates a webpage to be compatible with screen readers, without having received training on how screen reader users navigate the internet. For this reason, the development of guidelines and standards is crucial, as well as support for training initiatives, such as the IMPACT project $^{9}$ (2019-2022), that start from a user-centred basis.

\section{Professionals in the accessibility field}

One of the main problems in the accessibility field is the lack of professionals trained in the different processes of the service. As Matamala and Orero (2006) and Pereira and Lorenzo (2006) point out, on many occasions the emphasis is placed on technical aspects, which are essential for the provision of the different accessibility services to reach the users. However, more attention needs to be placed on other fundamental competences, such as understanding the accessibility needs and preferences of the different users, linguistic competence to be able to transmit the written and/or oral message correctly, service competence to be able to carry out the service properly, or promotion to be able to involve all stakeholders in the accessibility chain. There is an increasing percentage of accessibility services, but the importance of quality and the need for trained professionals in the different phases that are part of the accessibility service remains unsolved. As stated in the report of the European Federation of Hard of Hearing (EFHOH 2015, 19)

It is essential that quality is maintained alongside increasing quantity; otherwise the purpose of subtitling is lost. One way to ensure quality is maintained is to invest in the training of live subtitling translators and speech-to-text interpreters. Such investment will only increase the accessibility of subtitling.

For the correct implementation of all accessibility services, it is necessary to train professionals to acquire the necessary knowledge and skills for the provision of accessibility services. Much of the training is conducted outside academic institutions, without specific recognition or a concrete definition of the necessary competences. Likewise, it is important to promote a greater knowledge transfer between academia and industry through the profile of the "practisearcher" (Mendoza Domínguez and Matamala 2019), which combines academic knowledge with real professional practice. Additionally, a greater transfer of knowledge between standardisation agencies, academia and industry is also relevant for a correct implementation of the standards that regulate accessibility services (Matamala and Orero 2013, Oncins and Orero 2021).

\subsection{New professional profiles in the accessibility field}

In the last decade, various Erasmus + projects have been developed in the field of accessibility to train new professional profiles for European accessibility services such as the audio description expert (Perego 2017), the accessibility manager for the performing arts (Orero 2017, Matamala and Orero 2019, Remael et al. 2019), the expert in easy-to-understand language 
in audiovisual media (Matamala 2019) or the expert in live subtitles (Bernabé and Orero 2018, Eugeni and Bernabé 2019, Oncins et al. 2019). Although these projects have focused on services to ensure that media content is accessible, it is important to highlight the growing importance of technologies to be able to offer these services, which is why there was a need to scale accessibility to a transversal level, that of accessibility in ICT products and services, which is the main aim of the IMPACT project. In addition, the increasing incorporation of new technological developments in the different processes of the creation and delivery of accessibility services, especially in subtitling (such as respeaking, automatic voice recognition, or artificial intelligence), result in a demand for new profiles with greater mastery of the technology (Oncins et al. 2019, Arumí-Ribas and Romero-Fresco 2008). It is important to emphasise that these projects, focused on the development of new professional profiles, are based on the acquisition of competencies not only related to the linguistic and cultural aspects of the service, but also other relevant competencies, some of which have traditionally been related to vocational practices. This is the case of entrepreneurship and service competence, and accessibility promotion and stakeholders engagement competence. Both competences have not been covered in conventional training programs for a long time and are now considered key competences in the 'European Qualification Framework for Lifelong Learning' (EQF 2008) ${ }^{10}$. The main objective of these projects is the definition of new professional profiles in media and digital accessibility that ensure the social need to guarantee accessible content and services for all audiences, regardless of their abilities.

\subsection{Current training programs in the accessibility field}

This section will present the main aims of current ERASMUS+ projects which include: EASIT, focused on audiovisual easy-to-understand content; LTA, focused on live subtitling; IMPACT, focused on web accessibility, and IDE@, focused on accessible teaching practices. All these Erasmus+ projects are strategic partnerships between public and private stakeholders from the university, the industry and end-user associations. They share the same aim, which is to create materials to train experts on providing and improving accessibility services in different fields and contexts related to media, such as scenic arts, cinema, or live events, to name some. They have been designed in line with the EC initiative "An agenda for the modernisation of higher education" (2017), which aims to equip people with the right skills for our digital and modern society.

The main objective of the EASIT (Easy Access of Social Inclusion Training) project is to define the skills of professionals who create content that is easy to read and easy to understand, as well as to create educational materials to train them. EASIT investigates how existing audiovisual access services, such as audio description, audio subtitling, or subtitling, could be merged with Easy Language (IFLA 2010, ILSMH 1998, Inclusion Europe 2014, Bredel and Maass 2016) or Plain Language (Bailey 1990, Cutts 1995, Cheek 2010).

The LTA (Live Text Access) project aims to fill a gap in the training of professionals in the real-time intralingual subtitling practice using respeaking and Velotype techniques. Live subtitling has mainly been developed in the television context, but it can also be used in educational, cultural, or parliamentary contexts, among others. The materials created in this program are open source and certified with the aim of training professionals with the needed skills to face this emerging professional activity in different working contexts.

The IMPACT project (Inclusive Method based on the Perception of Accessibility and Compliance Testing) aims to define the skills and competencies that an educator or mediator in ICT accessibility must acquire and master for the correct implementation of the harmonised European standard for digital accessibility EN 301 549. The recent adoption and entry into force of the Web Accessibility Directive has highlighted the scarce training in the web accessibility field outside the technological context (Oncins et al. 2020).

Finally, the IDE@ project (Implementing a Digital E-learning @Iternative) (2021-2023) aims to set up an accessible and inclusive distance learning curriculum focused on vocational training (VET) centres, and trainers that had to adapt to distance education due to the COVID-19 pandemic. In order to reach this general objective, the project will first identify the obstacles for providing accessible distance training, it will then identify the teaching skills to be developed in order to ensure accessible teaching and will define the skills and create materials to ensure successful distance learning experiences with accessibility in mind.

\section{Conclusions}

The EU has significantly improved the legal framework on accessibility with the Web Accessibility Directive (2016), the updated Audiovisual Media Services Directive (2018), and the European Accessibility Act (2019). This legal framework establishes the accessibility levels for certain digital and media products and services. Additionally, it underlines the importance of accessible media for all citizens. The implementation of the accessibility services is not only a moral responsibility; it also means encouraging public and private media service providers to increase the quantity and quality of their accessibility services. The implementation of the EU legislation at a national level ensures that products are accessible to all people, regardless of their abilities. Mindsets must move from a diversity to an inclusive perspective (Taylor, 2017). Accessibility should be regarded as both a concern and a benefit for us all, and not merely for a few so-called minorities. 
It is also necessary to highlight that the continuous technological developments, such as automatic speech recognition used in subtitling, voice synthesis used in audio description, and avatars used for sign language require professionals with a higher mastery of technological skills. These developments could be seen as a threat for professionals working in the accessibility field, since part of the human task is replaced. But percentages set by legislation should be compliant not only in terms of quantity but also in terms of quality. Therefore, human-based processes to ensure the quality of the services are still essential. The skills and competences of accessibility professionals are highly needed in many contexts where technology is not mature enough to ensure quality accessible services. Additionally, accessibility professionals are key players for promoting and raising awareness about accessibility, as they are usually mediators between end-users and organisations.

\section{Acknowledgments}

This work has been partially funded by ERASMUS+ IDE@ 2020-1-FR01-KA226-VET-095584, IMPACT 2019-1-FR01-KA204-062381, ERASMUS+ LTA 2018-1-DE01-KA203-004218, ERASMUS+ EASIT 2018-1-ES01-KA203-05275. The authors are members of TransMedia Catalonia, an SGR research group funded by Secretaria d'Universitats i Recerca del Departament d'Empresa i Coneixement de la Generalitat de Catalunya (2017SGR113).

\section{Notes}

https://www.un.org/development/desa/disabilities/conven tion-on-the-rights-of-persons-with-disabilities/article-9-acce ssibility.html

2 https://www.eud.eu/news/training/audiovisual-media-servi ces-directive-toolkit-transposition/\#site-header

${ }^{3}$ https://Itaproject.eu

${ }^{4} \mathrm{http}: / /$ www.adlabproject.eu

${ }^{5} \mathrm{https}: / / w w w . a d l a b p r o . e u$

${ }^{6} \mathrm{https}$ ://pagines.uab.cat/easit/en

${ }^{7}$ https://www.etsi.org/deliver/etsi_en/301500_301599/30154 9/03.01.01_20/en_301549v030101a.pdf

${ }^{8}$ https://www.w3.org/TR/WCAG21/

${ }^{9}$ https://impact-access.eu

$10 \mathrm{https}: / / w w w . c e d e f o p . e u r o p a . e u / e n / e v e n t s-a n d-p r o j e c t s / p r$ ojects/european-qualifications-framework-eqf

\section{Bibliography}

AENOR. 2019. Accessibility requirements for ICT products and services UNE-EN 301549:2019. Retrieved from: https://www.une.org/encuentra-tu-norma/busca-tunorma/norma?c=N0061677 (consulted 21/04/2021)

AENOR. 2018. EX Easy to read. Guidelines and recommendations for the elaboration of documents UNE 153101: 2018. Retrieved from: https://www.une.org/ encuentra-tu-norma/busca-tu-norma/norma?c=N0060036 (consulted 21/04/2021)

AENOR. 2012. Subtitling for deaf and hard-of-hearing people UNE 153010: 2012. Retrieved from: https:// www.une.org/encuentra-tu-norma/busca-tu-norma/ norma/?c=N0049426 (consulted 21/04/2021)
AENOR. 2007. Guidance on the use of the Spanish Sign Language on computer networks UNE 139804:2007. Retrieved from: https://www.une.org/encuentra-tu-norma/ busca-tu-norma/norma?c=N0040404 (consulted 21/04/ 2021)

AENOR. 2005. Audio description for visually impaired people. Guidelines for audio description procedures and for the preparation of audio guides UNE 153020:2005. Retrieved from: https://www.une.org/encuentra-tunorma/busca-tu-norma/norma?c=N0032787 (consulted 21/04/2021)

Arumí Ribas, Marta and Romero-Fresco, Pablo. 2008. "A Practical Proposal for the Training of Respeakers" in JosTrans 10: 106-127

Bailey, Edward P. 1990. The Plain English approach to business writing. Oxford: OUP.

Bredel, Ursula and Maaß, Christiane. 2016. Leichte Sprache. Theoretische Grundlagen, Orientierung für die Praxis. Berlin: Duden.

Cheek, Anette. 2010. "Defining plain language" in Clarity: 64, 5-15.

Cutts, Martin. 1995. The Plain English Guide. Oxford: OUP.

Bernabé Caro, Rocío and Orero, Pilar. 2018. "Quality training in real time subtitling across EU and EU languages." in BFC2018: 4-6.

Braun, Sabine and Orero, Pilar. 2010. "Audio description with audio subtitling - an emergent modality of audiovisual localisation" in Perspectives, 18:3, 173-188, DOI: 10.1080/0907676X.2010.485687

EBU. 2019. PSM Access services survey. Retrieved from: https://www.ebu.ch/publications/research/members only/report/msp-services-dacces (consulted 21/04/2021)

Eugeni, Carlo. 2016. "Respeaking at BBC" in CoMe I, (1): 97-107.

Eugeni, Carlo and Bernabé Caro, Rocío. 2019. "The LTA project: Bridging the gap between training and the profession in real-time intralingual subtitling" in Linguistica Antverpiensia, New Series: Themes in Translation Studies, 18: $87-100$.

European Commission (EC). 2019. European Accessibility Act. Retrieved from: https://eur-lex.europa.eu/ legal-content/EN/TXT/PDF/?uri=CELEX:32019L0882\&fro $\mathrm{m}=\mathrm{ES}$ (consulted 21/04/2021)

European Commission (EC). 2018. Audiovisual Media Services Directive (AVMSD). Retrieved from: https://eur-lex.europa.eu/legal-content/EN/TXT/ ?uri=LEGISSUM\%3Aam0005 (consulted 21/04/2021)

European Commission (EC). 2018. Digital Single Market: updated audiovisual rules. Retrieved from: http:// europa.eu/rapid/press-release_MEMO-18-4093_en.htm (consulted 21/04/2021)

European Commission (EC). 2012. European Union Regulation 1025/ 2012 on European Standardization. Retrieved from: https://eur-lex.europa.eu/legal-content/EN/ TXT/?uri=celex\%3A32012R1025 (consulted 21/04/2021)

IFLA. 2010. Guidelines for easy-to-read materials. Retrieved from: https://www.ifla.org/files/assets/hq/publica tions/professional-report/120.pdf. (consulted 21/04/2021)

ILSMH European Association. 1998. Make it Simple: European Guidelines for the Production of Easy-toRead Information for People with Learning Disability for authors, editors, information providers, translators and other interested persons. Retrieved from: https:// digitalcommons.ilr.cornell.edu/cgi/viewcontent.cgi?article= $1271 \&$ context=gladnetcollect (consulted 21/04/2021)

Inclusion Europe. 2014. Information for all: European 
standards for making information easy to read and understand. Retrieved from: https://www.inclusion-europe. eu/easy-to-read (consulted 21/04/2021)

International Organization for Standardization. 2019. Information technology - User interfaces - Part 1: Guidance on making written text easy to read and easy to understand ISO/IEC CD 23859-1. Retrieved from: https:// www.iso.org/standard/77178.html (consulted 21/04/2021)

International Organization for Standardization. 2018. Information technology - User interface component accessibility - Part 23: Visual presentation of audio information (including captions and subtitles) ISO/IEC 20071-23:2018. Retrieved from: https://www.iso.org/obp/ ui/\#iso:std:iso-iec:20071:-23:ed-1:v1:en (consulted 21/04 /2021)

International Organization for Standardization. 2017. Information technology - User interface component accessibility - Part 25: Guidance on the audio presentation of text in videos, including captions, subtitles and other on-screen text. ISO/IEC TS 20071-25:2017. Retrieved from: https://www.iso.org/standard/69060.html (consulted 21/04/2021)

International Organization for Standardization. 2015. Information technology - User interface component accessibility - Part 21: Guidance on audio descriptions ISO/IEC TS 20071-21:2015. Retrieved from: https://www. iso.org/standard/63061.html (consulted 21/04/2021)

International Organization for Standardization. 2012. Information technology -- W3C Web Content Accessibility Guidelines (WCAG) 2.0 ISO/IEC 40500:2012. Retrieved from: https://www.iso.org/standard/58625.html (consulted 21/04/2021)

Lambourne, Andrew. 2006. "Subtitle Respeaking". In Intralinea, Special Issue: Respeaking. Retrieved from: http://www.intralinea.org/specials/article/Subtitle_ respeaking. (consulted 21/04/2021)

Matamala, Anna. 2019. "From easy-to-read texts to easy-to-understand audiovisual content: practice and training" in Euroscientist. Special issue The Social Value of European Research on Media Accessibility. Retrieved from: https://www.euroscientist.com/from-easy-to-readtexts-to-easy-to-understand-audiovisual-content-practiceand-training/ (consulted 21/04/2021)

Matamala, Anna. 2007. "La accesibilidad en los medios: aspectos lingüísticos y retos de formación". In PérezUgena, Á. (ed.). La accesibilidad en la era de la tv digital. Madrid: Laberinto.

Matamala, Anna and Orero, Pilar. 2019. "Training experts in inclusive practices for an equity on access to culture in Europe". In S. Halder, V. Argyropoulos (eds) Inclusion, equity and access for individuals with disabilities. Palgrave Macmillan: 263-280.

Matamala, Anna and Orero, Pilar. 2018. "Standardising accessibility: transferring knowledge to society" in Journal of Audiovisual Translation, 1(1): 139-154.

Matamala, Anna and Orero, Pilar. 2006. "Integración de la accesibilidad en los medios en los estudios de traducción" in Comunicación presentada en el Congrés Internacional de Docència Universitària i Innovació. UAB: Barcelona.

Mendoza Domínguez, Núria and Matamala, Anna. 2019. "Panorama de la enseñanza de la audiodescripción en España: Resultados de un cuestionario" in MonTI 11: 155-185.

Oncins, Estella; Altinier, Armony and Fitzpatrick, Donal. 2020. "Mapping the European Digital Accessibility field" in Proceedings of the 9th International Conference on
Software Development and Technologies for Enhancing Accessibility and Fighting Info-exclusion (DSAI 2020), December 2-4, 2020, Online, Portugal.

Oncins, Estella and Orero, Pilar. 2021. "Let's put standardisation in practice" in Hikma 20,1: 71-90.

Oncins, Estella. 2020. "Accessibility Training for the New Digital World: The IMPACT project" in Euroscientist. Retrieved from:https://www.euroscientist.com/accessibilitytraining-for-the-new-digital-world-the-impact-project/ (consulted 21/04/2021)

Oncins, Estella; Eugeni, Carlo and Bernabé Caro, Rocío. 2019. "The Future of Mediators for Live Events: LTA Project - Academic and Vocational Training" in Cultus: the Journal of Intercultural Mediation and Communication 2: 129-153.

Orero, Pilar. 2017. "The professional profile of the expert in media accessibility for the scenic arts" in Rivista internazionale di tecnica della traduzione RIIT 19: 143-161.

Orero, Pilar. 2006. “¿Quién hará la audiodescripción comercial en España? El futuro perfil del descriptor". In Jiménez, C. (ed.). Traducción y accesibilidad. Subtitulación para sordos y audiodescripción para ciegos: nuevas modalidades de Traducción Audiovisual. Granada: Comares.

Orero, Pilar. 2005. "Audio Description: Professional Recognition, Practice and Standards in Spain" in Translation Watch Quarterly, 1: 7-18.

Orero, Pilar and Matamala, Anna. 2013. "Standardising Audio Description" in Italian Journal of Special Education for Inclusion: 149-155.

Perego, Elisa. 2017. "Audio Description: A Laboratory for the Development of a New Professional Profile" in Rivista Internazionale di Tecnica della Traduzione, 19: 131-142.

Pereira, Ana M. and Lorenzo, Lourdes. 2006. "La investigación y formación en accesibilidad dentro del ámbito de la traducción audiovisual". In Gonzalo García, C. y P. Hernúñez (eds.). Libro homenaje a Valentín García Yebra, Madrid: Arco Libros

Puigdomènech, Laura; Orero, Pilar and Matamala, Anna. 2008. "The Making of a Protocol for Opera Audio Description". In Pegenaute, L., DeCesaris, J., Tricás, M. \& E. Bernal (Eds.) La traducción del futuro: mediación lingüística y cultural en el siglo XXI (pp.381-392). Barcelona: PPU.

Remael, Aline; Orero, Pilar; Black, Sharon and Jankowska, Anja. 2019. "From translators to accessibility managers: How did we get there and how do we train them?" in MonTi, 11: 131-154.

Reviers, Nina (2016). "Audio description services in Europe: an update" in Jostrans 26: 232-246.

Taylor, Chris (2017). "Getting Our House in Order: Moving from Diversity to Inclusion" in The American Archivist: Spring/Summer 2017, 80 (1): 19-29.

Theunisz, Mildred. 2002. Audio subtitling: A new service in Netherlands making subtitling programmes accessible. Retrieved from: http://www.sb-belang.nl/ (consulted 21/04/2021)

Vercauteren, Gert. 2007. "Towards a European Guideline for Audio Description”. In Díaz Cintas, J., Orero, P. and Remael, A. (Eds). Media for All: Subtitling for the Deaf, Audio Description and Sign Language (pp. 139-149). Amsterdam: Rodopi. 